\title{
Online educational counselling for students with special needs: building rapport
}

\author{
Margaret Debenham, Denise M. Whitelock, Pat Fung and Judy M. Emms \\ The Institute of Educational Technology, The Open University, \\ email:m.debenham@open.ac.uk
}

This paper reports the findings from a study that investigated the effects of providing online counselling for undergraduate students with long-term health problems. Issues associated with learning at a distance for such students include fatigue, manual dexterity, academic and social isolation, together with a need for better interactive communication with support agencies (Debenham, 1996a). The results of a feasibility study undertaken in 1996 suggested that for students with special needs personal rapport with their educational counsellor is considered important for problems to be aired and addressed (Debenham, 1998a). This raises interesting questions relating to how such rapport can be developed using computer-mediated communication (CMC). Participants in the study reported appreciation of a small amount of informal contact with the counsellor in a closed peer-group conference; this conference is described in Debenham (1996b). Building on this finding, a main study was undertaken which was modified by the addition of a counselling topic - $a$ 'Virtual Study' for the counsellor - within this conference area (Debenham, 1998b). The counsellor was encouraged to participate informally in the other student-led topics. This added a group dimension to the study. The results are encouraging: increased levels of motivation and enjoyment of the study process were reported by more than three-quarters of the sample and in the degree of autonomy by more than half the sample. These findings throw light on the support of students with special needs and also contribute to the development of knowledge in the wider fields of academic advising and the use of CMC in distance education.

\section{Introduction}

Distance learners with long-term health problems face a number of difficulties in their studies. These include severe fatigue, problems of manual dexterity, academic and social isolation, together with a need for better interactive communication with support agencies (Debenham, 1996a). It was expected that the use of computer-mediated communication (CMC) could provide a possible way to tackle all four problems described above. 
Computer conferencing might also prove to be an effective route for facilitating educational counselling services for such students. The role of an educational counsellor in the Open University, the context of the study reported here, is based on a developmental view of counselling and advising (Bailey et al., 1996; Frost, 1991; UDACE, 1986). This approach aims to encourage the personal development and progress of the learner as a whole person. A feasibility study was undertaken in 1996 to investigate the effects of providing access to an educational counsellor online within the environment of the "Virtual Campus' (computer conferencing system) of the university. The results of this study suggested that for students with special needs, personal rapport with their educational counsellor is considered important for problems to be aired and addressed. This raises questions relating to how such rapport can be developed using computer-mediated communication (CMC). New features introducing an element of interactive group discussion between the counsellor and students were adopted for the main study. The methodology and results of this study are described in the following section.

\section{The main study}

Thirteen part-time undergraduate distance learners (seven male, six female) from seven different regions participated in this study. They included the six who had taken part in the earlier feasibility study. All thirteen had previously completed undergraduate courses with the university. The new sample (four male, three female) was drawn from students with a similar level of health difficulties who had had access to the self-help areas of the 'Virtual Campus' in the previous year. The intention was to provide a level playing field for the whole group in every respect other than online educational counselling. This strategy would enable comparisons to be made between the experience of the two samples at the end of the study. Questionnaires were issued to the subjects at the beginning, mid-session and end of the academic year. The counsellor was asked for a pre-participation statement at the beginning of the year and to complete a questionnaire at the end of the year.

In 1997 the Open University adopted Soft Arc's FirstClass, an icon-based program, for general use to support the 'Virtual Campus'. This superseded the text-based CoSy4/ Wigwam software in use during the period of the earlier study.

\section{Introducing a group dimension to online educational counselling}

The online educational counselling provision was modified for the main study by features that added a group dimension to the online environment. Firstly, a counselling topic was set up within the closed area of the existing peer-group conference, DOORway. Within this topic only, metaphorically speaking the 'Virtual Study', the counsellor was in charge of the discussion. This enabled students to raise issues that they felt were relevant to the whole group within a confidential environment. It permitted both 'one-to-many' and 'many-tomany' interactive communication, and consequently the possibility of wider exchange of information relating to study matters. Additionally the counsellor was encouraged to participate informally, as a guest, in the five student-led topics of the conference. Figure 1 shows the icon-based DOORway desktop as it appeared on the computer screen of each member of the conference during the period of the main study.

It was expected that these two measures might combine to create a relaxed atmosphere 


\begin{tabular}{|c|c|c|c|}
\hline Doorway & & $\square$ & $X$ \\
\hline Conference & 15 files 6 Folders \\
\hline & & \\
\hline & & \\
\hline
\end{tabular}

Figure 1:The DOORway Desktop - introducing an interactive group dimension to personal educational counselling online

where students and counsellor could 'get to know each other'. In this way it might be possible steadily to build a relationship of rapport so that educational counselling could be both readily sought and given (either by one-to-one email or in the group) and so increase the effectiveness of interactive contact between student and counsellor. An 'information' topic accessed via the main DOORway icon enabled formal dissemination of information to the group by the student moderator and the researcher.

\section{Results}

At the end of the study the data taken from the student questionnaires and counsellor records show that there had been a marked increase in the level of usage of the online counsellor's services compared with that of the feasibility study. The majority of the sample (ten students) had contacted the online counsellor for help/advice during the year. The data relating to the number of issues raised with the counsellor in respect of the whole sample is presented in Table 1.

\begin{tabular}{|c|c|c|c|c|c|}
\hline One-to-one e-mail & $\begin{array}{l}\text { Total no. } \\
\text { of issues }\end{array}$ & $\begin{array}{c}\text { DOORway counselling } \\
\text { topic }\end{array}$ & $\begin{array}{l}\text { Total no. } \\
\text { of issues }\end{array}$ & $\begin{array}{l}\text { DOORway } \\
\text { (other topics) }\end{array}$ & $\begin{array}{l}\text { Total no. } \\
\text { of issues }\end{array}$ \\
\hline $\begin{array}{l}\text { Help with special needs } \\
\text { arrangements }\end{array}$ & 8 & $\begin{array}{l}\text { Information in relation to } \\
\text { studies }\end{array}$ & 7 & Informal chat & 20 \\
\hline $\begin{array}{l}\text { Information in relation to } \\
\text { studies }\end{array}$ & 5 & $\begin{array}{l}\text { Information in relation to } \\
\text { special needs. }\end{array}$ & 6 & Information & 6 \\
\hline $\begin{array}{l}\text { Personal support when } \\
\text { experiencing difficulties }\end{array}$ & 4 & Advice in relation to studies & 1 & Advice on study matters & 3 \\
\hline Advice in relation to studies & 2 & Other & 2 & Other & - \\
\hline Other & 1 & & & & \\
\hline
\end{tabular}

Table 1: Total number of issues raised (categorized by type of issue) for whole sample 


\begin{tabular}{|c|c|c|c|c|c|c|c|c|c|}
\hline & \multicolumn{3}{|c|}{ Motivation } & \multicolumn{3}{|c|}{ Autonomy } & \multicolumn{3}{|c|}{ Enjoyment } \\
\hline & & $n=13$ & & & $n=13$ & & & $n=13$ & \\
\hline & $\begin{array}{l}\text { Male } \\
n=7\end{array}$ & $\begin{array}{c}\text { Female } \\
n=6\end{array}$ & Total & $\begin{array}{l}\text { Male } \\
n=7\end{array}$ & $\begin{array}{c}\text { Female } \\
n=6\end{array}$ & Total & $\begin{array}{l}\text { Male } \\
n=7\end{array}$ & $\begin{array}{c}\text { Female } \\
n=6\end{array}$ & Total \\
\hline Great increase & - & 2 & 2 & - & 2 & 2 & 1 & 2 & 3 \\
\hline Some increase & 5 & 2 & 7 & 3 & 1 & 4 & 3 & 2 & 5 \\
\hline A little increase & - & 1 & 1 & 1 & - & 1 & 1 & 1 & 2 \\
\hline No change & 2 & - & 2 & 3 & 2 & 5 & 2 & - & 2 \\
\hline Less than before & - & - & - & - & - & - & - & - & - \\
\hline $\begin{array}{l}\text { Withdrawn from } \\
\text { study early in year } \\
\text { through illiness }\end{array}$ & - & 1 & 1 & - & 1 & 1 & - & 1 & 1 \\
\hline
\end{tabular}

Table 2: Changes in perceived levels of student motivation, autonomy and enjoyment of the study process at condusion of main study

Each query raised resulted in an exchange of messages between the student and counsellor. Nine of the subjects said that, given the choice, they would choose access to an online counsellor in preference to traditional routes. Possible reasons for this are explored later in the paper. One student thought both routes desirable, and two remained unsure. The students' responses to the question of whether they had experienced any changes in levels of motivation, autonomy and enjoyment of the study process by the end of the main study are presented in Table 2.

The results indicate that more than three-quarters of the sample reported an increase in motivation and enjoyment of their studies and more than half experienced a greater feeling of autonomy.

What then were the reasons for these encouraging changes? Data collated from the questionnaires indicates that informal interactive contact in the area of the peer-group conference had been effective in promoting a relationship of mutual trust and rapport between the online counsellor and the students. The conference had played a key role in providing a secure base both for access to online educational counselling and for peer support. It was ranked as the primary or secondary reason (of six options) for logging on to the 'Virtual Campus' by nine of the sample; seven of the sample ranked online counselling as next in importance. Recent research by Preece and Ghozati (1998) into empathic online communities identifies the importance of a strongly shared mutual interest base in such groups. In the case of the present study there was a doubly shared interest, that of Open University study and problems associated with disability.

A summary of the freeform answers in the student questionnaires on the value of contact with the online counsellor in the conference environment suggest that there are a number of possible advantages related to group discussion. These results are presented in Table 3. 


\begin{tabular}{|c|c|}
\hline ALT-J & Volume 7 Number 1 \\
\hline Getting to know counsellor informally made her more approachable & 4 students \\
\hline Created a feeling of friendliness & 3 students \\
\hline Informal contact relaxed hierarchical barriers, made all feel on more equal terms & 2 students \\
\hline Helped counsellor to develop knowledge of problems faced & 2 students \\
\hline Allowed for a more rounded relationship & I student \\
\hline Counsellor brought in-depth knowledge of OU study system to group discussion & I student \\
\hline $\begin{array}{l}\text { Counsellor may gather knowledge of possible solutions to problems from student } \\
\text { discussion of their experience }\end{array}$ & I student \\
\hline
\end{tabular}

Table 3: Advantages of group discussion in building rapport

One way of looking at these data could be that informal contact in the student-led topics might be considered analogous to chatting to a tutor in the bar after a face-to-face tutorial. In this setting students will often feel more relaxed and able to open up discussion informally. The fact that two students mentioned the relaxation of hierarchical boundaries suggests that 'meeting' in the student-led areas of the conference environment had a positive effect on feelings of autonomy and control. The final two points indicate the potential value of group discussion for sharing and dissemination of knowledge both for the counsellor and the students. In the end-of-year questionnaire, the counsellor commented that, over the course of the academic year, her use of one-to-one email had increased as her relationship developed with the students in the peer-group conference. This suggests that student confidence in the counsellor had resulted from the building of rapport through group contacts. However, these inferences are to be pursued in a follow-up interview study.

In respect of the issue of motivation, there is evidence drawn both from a student questionnaire and from the counsellor's records that support and reassurance provided by the counsellor had enabled one particular student who had been on the point of withdrawing from her studies to continue. She successfully completed her course. In two other instances where students withdrew from their courses, continuity of contact was maintained in the DOORway conference and they were encouraged to re-register in the following year. The counsellor's records show that in six instances she had liaised with others in the university on behalf of students, usually regarding special needs. Use of CMC provides a fast and convenient way for such contacts (sometimes with more than one department) to be made. The result was that she had been able to provide unobtrusive personal help at the point of need.

In relation to the asynchronous use of $\mathrm{CMC}$, two of the subjects specifically commented that it removed their fear of intrusion on the counsellor's personal time (by telephone); messages could be uploaded at a time convenient to themselves knowing that they would be read at her convenience. This may be of particular importance for this category of students (data collected both in the feasibility study and current study suggests that working flexibly, sometimes at unsociable hours, to accommodate health difficulties is not 
unusual). Two students expressed a preference for contact via email rather than voice or face-to-face in an upsetting situation. This is also interesting since it runs counter to the widely held view (initially held by the online counsellor) that visual and aural cues are helpful in the creation of empathy in such situations. Nine of the sample considered that the use of an off-line reader was 'very important' to their use of the 'Virtual Campus' and a further two 'quite important'. It had permitted messages to be prepared and read over a period of time. This is of particular relevance to those with dexterity problems; in such cases it can take considerable time for them physically to prepare a message. Use of an offline reader removes the worry of running up large telephone bills. In the final section that follows, the conclusions drawn from these results are presented.

\section{Conclusions}

The results suggest that CMC can provide an effective route for access to an educational counsellor. They indicate that it is possible to foster a relationship of mutual trust and rapport between counsellor and students within a closed group. Confidence to approach the counsellor with problems was promoted. The increased levels of motivation, autonomy and enjoyment reported by the majority of the sample suggest a perception of benefit to their studies. Issues related to these findings are to be the subject of a follow-up interview study. In this study the perceived effects of the relaxation of hierarchical boundaries in the environment of the peer group conference on student feelings of autonomy and motivation will be investigated. The reasons for the expressed student preference for the use of email in a distressing situation will also be explored. It could be that the medium facilitates communication, which is at the same time both intimate and distancing, in addition to permitting a more considered dialogue between counsellor and student than might otherwise be possible. In a wider context, the results suggest that it would be valuable to explore further the role which empathic online communities might play in a distancelearning environment. There may be other groups for whom this approach could prove beneficial - for example single parents of young children who may also sometimes be house-bound and socially isolated - and for whom CMC support and educational counselling could bring equivalent gains.

\section{References}

Bailey, D., Brown, J. and Kelly, P. (1996), 'Academic advice, personal counselling and onprogramme guidance in the Open University', Personal Tutoring and Academic Advice, 32-7, Higher Education Quality Council.

Debenham, M. (1996a), 'Barriers to study for Open University students with long term health problems: a survey', Student Research Centre Report No. 105, Milton Keynes: Institute of Educational Technology, Open University.

Debenham, M. (1996b), 'DOORway (Disabilities, Opportunities and OutReach): interactive computer conferencing system which provides peer group support in distance learning', in Klaus, J., Auff, E., Kremser, W. and Zagler, L. (eds.), Proceedings of Interdisciplinary Aspects of Computers Helping People with Special Needs '96 (ICCHP'96), 183-7, Vienna and Munich: R. Oldenbourg. 
Debenham, M. (1998a), 'CMC and disability support: on-line counselling - a feasibility study', Student Research Centre Report No. 146, Milton Keynes: Institute of Educational Technology, Open University.

Debenham, M. (1998b), 'CMC and disability support: on-line educational counselling: building rapport', Student Research Centre Report (in preparation), Milton Keynes: Institute of Educational Technology, Open University.

Frost, S. H. (1991), Academic advising for student success: a system of shared responsibility', ASHE-ERIC Higher Education Report 3, Washington DC: George Washington University, School of Education and Human Development.

Preece, J. and Ghozati, K. (1998), 'Empathic communities: exploration of 100 online communities', http:/www.ifsm.umbc.edu/profs/preece.html, University of Maryland.

UDACE (1986), The Challenge of Change: Developing Educational Guidance for Adults, Leicester: Unit for the Development of Adult Continuing Education; National Institute of Adult Continuing Education. 